\title{
Function of a landscape lake in the reduction of biotoxicity related to trace organic chemicals from reclaimed water
}

\author{
Xiaoyan Y. Ma ${ }^{\mathrm{a}}$, Xiaochang C. Wang ${ }^{\mathrm{a}}$, Donghong Wang ${ }^{\mathrm{b}}$, Huu Hao Ngo ${ }^{\mathrm{c}}$, Qiuya Zhang ${ }^{\mathrm{a}}$, \\ Yongkun Wang ${ }^{\mathrm{a}}$, Dinan Dai ${ }^{\mathrm{a}}$ \\ ${ }^{a}$ International Science \& Technology Cooperation Center for Urban Alternative Water Resources \\ Development; Key Lab of Northwest Water Resource, Environment and Ecology, MOE; Engineering \\ Technology Research Center for Wastewater Treatment and Reuse; Key Lab of Environmental \\ Engineering, Shaanxi Province; Xi'an University of Architecture and Technology, Xi'an, 710055, PR \\ China \\ ${ }^{b}$ State Key Laboratory of Environmental Aquatic Chemistry, Research Center for Eco-Environmental \\ Sciences, Chinese Academy of Sciences, Beijing 100085, PR China \\ ${ }^{c}$ School of Civil and Environmental Engineering, Faculty of Engineering and Information \\ Technology, University of Technology Sydney, Broadway, NSW 2007, Australia
}

\section{Highlights}

- The lake is a buffer zone in between reclaimed water production and reuse.

- Biotoxicity of reclaimed water decreased during open storage in a landscape lake.

- The dominating chemicals contributing to the biotoxicity were identified.

- The lake provided a favorable seminatural condition for micropollutants decay.

\begin{abstract}
The storage of water in a landscape lake can act as a buffer zone between reclaimed water production and reuse, but there is still uncertainty about the variation of water quality and toxic effects during the open-storage process. In this study, long-term sample collection, chemical analyses and biotoxicity assessments were conducted on reclaimed water before and after open storage in a landscape lake. The organic contents, in terms of chemical oxygen demand and total organic carbon, were found to be slightly higher in the lake water than that in the reclaimed water, but substantial reduction of the total concentration of 52 trace organic chemicals was obtained and microorganism toxicity, phytotoxicity, aquatic vertebrate toxicity and genotoxicity, were significantly weakened after open storage. Furthermore, the total risk quotient $\left(\mathrm{RQ}_{\text {Total }}\right)$ decreased from 5.12 (potential ecological risk level) in the reclaimed water to 0.18 (negligible ecological risk level) in the lake water. The removal of chlorpyrifos, dichlorphos and tetracycline was identified as the main reason for biotoxicity reduction after open storage. The seminatural environment of the landscape lake would have provided a favorable condition for the decay of toxic trace organic chemicals so that the stored water turned to be safer for further reuse.
\end{abstract}

\section{Keywords}

Biotoxicity; Trace organic chemicals; Reclaimed water; Open storage; Ecological safety 


\section{Introduction}

Augmentation of water sources by appropriate reuse of treated wastewater could effectively relieve growing water shortages, but concerns about the safety of reclaimed water often impede its reuse. One direct and effective method to guarantee the safety of water reuse is to monitor the pollutants, particularly trace organic chemicals, using advanced instrumental analysis methods [1]. However, it may not be practically feasible to monitor every potential pollutant because many of them are present only in trace amounts or may have unknown structures that are difficult to identify. Additionally, chemical analyses may not reflect the detrimental effects of the pollutants on aquatic organisms [2]. To complement the limitations of chemical analyses, many in vitro and in vivo bioassays have been developed to characterize the adverse effects of pollutants in reclaimed water, including their cytotoxicity, genotoxicity, endocrine disrupting effect, photosynthesis inhibition effect, increasing oxidative stress response, and so on [3], [4],[5] and [6]. Moreover, many websites and organizations, such as the Persistent, Bioaccumulative, and Toxic Profiles, the ECOTOXicology Knowledgebase, Acute Toxicity Database of the Columbia Environmental Research Center collect experimental and predicted toxicological data of individual chemicals involving species at many trophic levels. That is conductive to the toxicological analyses of pollutants in reclaimed water. A combination of chemical analyses and toxicological analyses can further provide additional information on the ecological safety of reclaimed water reuse.

For water reuse, storage is usually an indispensable intermediate link between reclaimed water production and utilization. Traditionally, the reclaimed water is stored in a nearly enclosed clean-water tank following the treatment process in a reclaimed water treatment plant. An alternative way that is gradually gaining acceptance for effective water reuse is to store the reclaimed water in an open space such as a reservoir, lake, or pond where certain natural processes may promote the stabilization or improvement of the reclaimed water quality [7]. Recharge of the reclaimed water into surface waters is recognized to be a storage approach for indirect potable reuse [8]. On the other hand, water landscaping is usually an important purpose of water reuse in urban area [9]. In this case, the water body receiving the reclaimed water for landscaping can also perform the function of water storage for subsequent environmental uses such as road washing and gardening. During this kind of open storage, the water quality may undergo variations due to the inevitable intrusion of nonpoint sources from the surroundings, and physical, chemical or even biochemical changes may occur in natural surface waters. However, there is little information about the ultimate effects of these actions on the stored water quality, especially regarding the safety of the water for reuse purposes.

This study was conducted by using a water reclamation and reuse system where a lake was constructed to receive the reclaimed water and perform the functions for both landscaping and open storage. To gain insight into the characteristics of water quality variation and its ecological safety after open storage of the reclaimed water under a seminatural condition, comprehensive investigations were conducted by chemical analyses and bioassays with a focus on trace organic chemicals and their bio-toxic effects. The selection of a bioanalytical 
battery for biotoxicity assessment was based on the notion that the pollutants in reclaimed water and lake water would interact with the species in an aquatic ecosystem by either direct discharge or indirect reuse. Therefore, four bioassays based on the species in three trophic levels of aquatic ecosystem were used here to comprehensively evaluate the nonspecific toxicity of waters, and genotoxicity as reactive toxicity was also measured in a complementary assay.

\section{Materials and methods}

\subsection{Description of a water reclamation and reuse system}

This study was based on a water recycle system shown in Fig. 1, which starts from groundwater supply for potable purpose, and then enters a circulation of used water collection, water reclamation by anaerobic-anoxic-oxic biological treatment followed by a membrane bioreactor $\left(\mathrm{A}^{2} \mathrm{O}-\mathrm{MBR}\right)$, and then reclaimed water distribution for various nonpotable purposes such as water landscaping, toilet flushing, and green-belt irrigation. All the collectable used water, including that from toilet flushing, was collected for source enlargement. The $\mathrm{A}^{2} \mathrm{O}-\mathrm{MBR}$ system had a treatment capability of approximately $2000 \mathrm{~m}^{3} /$ day and disinfection (by sodium hypochlorite) was performed as the final stage of the treatment. To meet the requirement for different water uses, about half of the reclaimed water was sent directly to a number of buildings for toilet flushing and the other half was transferred to a landscape lake located at the center of the campus. A noticeable feature of the water recycle system was the introduction of the lake which performs both the functions of landscaping and water storage (total storage volume about $5000 \mathrm{~m}^{3}$ ) for improving the availability of the reclaimed water through multi-step utilization. The depth of the lake was $0.8-1.0 \mathrm{~m}$ and the average hydraulic retention time (HRT) was about 5 days which was dynamically controlled by continuous inflow (the reclaimed water) and outflow (pumping for various uses).

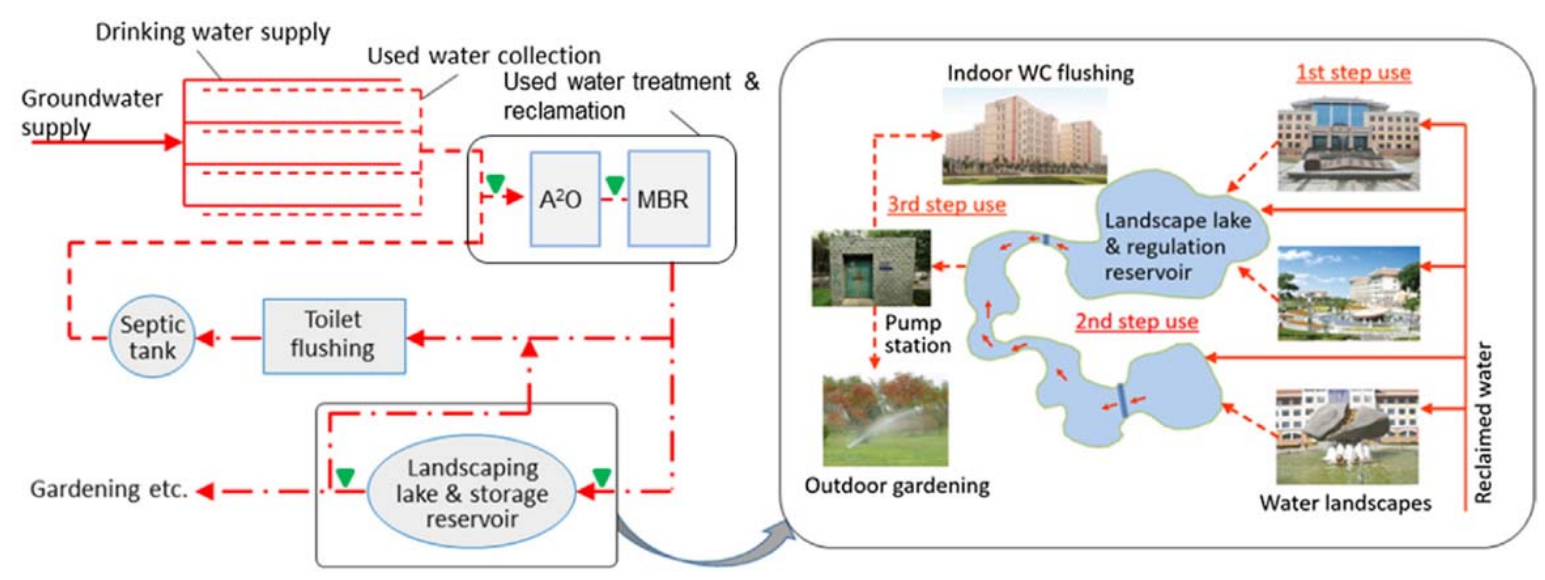

Fig. 1. The water cycle of the wastewater treatment and reuse system [10]. The inverted triangle represents the sampling site. 


\subsection{Sample collection and pretreatment}

Water samples were collected between December 2014 and June 2015 from the different sampling sites in the water reclamation and reuse system (Fig. 1). During the monitoring period, the sampling frequency was approximately twice a month for normal physicochemical indices analysis, once a month for micropollutants detection and bioassays.

Samples were collected on sunny days to get rid of the influence of rainfall and local runoff. On each sampling day, six liters of the reclaimed water (effluent from the $\mathrm{A}^{2} \mathrm{O}-\mathrm{MBR}$ system) and the same volume of the lake water (near the outlet) were collected into brown glass bottles and taken to the laboratory immediately. Each sample was filtered through a $0.7 \mu \mathrm{m}$ glass microfiber filter $\left(\Phi 150 \mathrm{~mm}\right.$; Whatman $\left.{ }^{\mathrm{TM}}\right)$. About $2 \mathrm{~L}$ of the filtered water was subjected to chemical analyses, and the remaining volume of the wastewater was directly or indirectly used in bioassays. The raw wastewater and secondary effluent (effluent of $\mathrm{A}^{2} \mathrm{O}$ ) were similarly treated to track the source of pollutants in the generated reclaimed water. Upon collection, the filtered samples were preconcentrated using solid-phase extraction (SPE) for bioassays and chemical analysis as described in detail in Section SI-1.

\subsection{Bioanalytical battery}

In total, five different bioassays were conducted to evaluate the biotoxicity effects of pollutants in reclaimed water and lake water. Luminescent bacteria toxicity test (acute toxicity test using Vibrio fischeri and Vibrio qinghaiensis sp. Q67), algal growth inhibition test using Chlorella vulgaris, fish larva mortality test using zebrafish larvae, and genotoxicity assay using the SOS/umu test were performed as described in Section SI-2.

\subsection{Chemical analyses}

Water quality analyses were firstly conducted by measuring chemical oxygen demand (COD), UV absorbance at $254 \mathrm{~nm}\left(\mathrm{UV}_{254}\right)$, total organic carbon (TOC), total phosphorus (TP), $\mathrm{NH}_{4}{ }^{+}-\mathrm{N}$, total nitrogen (TN), electric conductivity, turbidity and color according to the standard methods [11]. Specific ultraviolet absorbance (SUVA) was calculated as the ratio of $\mathrm{UV}_{254}$ over TOC.

For trace organic chemicals, instrumental methods were applied targeting 59 chemicals including 13 polycyclic aromatic hydrocarbons (PAHs), 3 pesticides, 16 phenols, and 27 pharmaceuticals. PAHs, pesticides and phenols were analyzed on an Agilent $6890 \mathrm{GC}$ coupled to a $5975 \mathrm{MS}(\mathrm{GC} / \mathrm{MS})$, equipped with a DB-5MS $(30 \mathrm{~m} \times 0.25 \mathrm{~mm} \times 0.25 \mu \mathrm{m})$ capillary column. Detailed instrument conditions for determining PAHs, pesticides and phenols are described in Table SI-1. Pharmaceuticals were analyzed on a UPLC coupled with a Waters Micromass Quattro Premier XE tandem quadruple mass spectrometer (UPLC$\mathrm{MS} / \mathrm{MS})$, equipped with a reversed-phase BEH C18 column $(100 \mathrm{~m} \times 2.1 \mathrm{~mm} \times 1.7 \mu \mathrm{m})$. Instrument conditions for analyzing different categories of pharmaceuticals were described in detail in previous studies [12]. 


\subsection{Ecological risk quotient estimation}

\subsubsection{Baseline toxicity prediction for chemicals towards aquatic organisms}

Toxicity of chemicals towards luminescent bacteria still does not have a sound available database. The prediction of $\mathrm{EC}_{50}-15$ min values of chemicals towards luminescent bacteria could resort to quantitative structure-activity relationships (QSARs). The typical baseline QSAR based on octanol-water partition coefficient $\left(\mathrm{K}_{\mathrm{ow}}\right)$ was applied to obtain the baseline toxicity of neutral PAHs. The liposome-water distribution coefficient $\mathrm{K}_{\text {lipw }}$ at a defined $\mathrm{pH}$, Dlipw ( $\mathrm{pH} 7$ ) was estimated and used in the QSARs to calculate the baseline toxicity of polar organic molecules towards $V$. fischeri, including pesticides, phenols, and pharmaceuticals. The detailed calculating procedures and explanation are shown in Section SI-3.

The predicted $\mathrm{EC}_{50}-96 \mathrm{~h}$ of trace organic chemicals to green algae, $\mathrm{LC}_{50}-48 \mathrm{~h}$ to daphnia and $\mathrm{LC}_{50}-96 \mathrm{~h}$ to fish were obtained from the ECOSARv1.10 database (US Environmental Protection Agency). In consideration of ecological safety, the most conservative effect level is used when predictions are identified from multiple classes. These acute toxicity data from four trophic levels were used to estimate predicted no-effect concentrations (PNECs). The chemicals for which the predicted values exceeded their solubility were excluded from the following risk quotient (RQ) estimation. The solubility values of chemicals were obtained from the experimental data in WSKOWWIN v. 1.42 .

\subsubsection{Methods for risk quotient estimation}

The RQ was quantified using the ratio between the measured environmental concentration

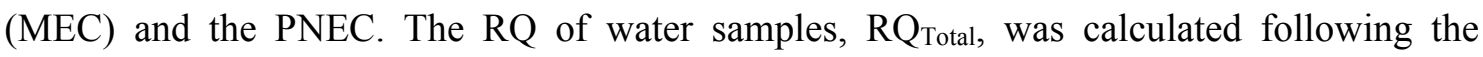
concept of concentration addition, where the combined effect of the components in the water sample is equal to the sum of their individual RQ, according to Eq. (1)[13].

$$
\mathrm{RQ}_{\text {Total }}=\sum_{i=1}^{\mathrm{n}} R Q_{i}=\sum_{i=1}^{n} \frac{\mathrm{MEC}_{\mathrm{i}}}{\mathrm{PNEC}_{\mathrm{i}}}
$$

The PNEC of each chemical was estimated using the ratio between its acute toxicity $\mathrm{L}(\mathrm{E}) \mathrm{C}_{50}$ value and an assessment factor (AF) (Eq. (2)) [14].

$$
\mathrm{PNEC}=\frac{\mathrm{L}(\mathrm{E}) \mathrm{C}_{50}}{\mathrm{AF}}
$$

The lowest $\mathrm{L}(\mathrm{E}) \mathrm{C}_{50}$ value of the four representative species, microorganism, algae, daphnia, and fish, was selected to estimate PNEC. The AF was set as 1000 in accordance with the suggestion of the Technical Guidance Document of the European Commission and Guidance for the Implementation of REACH [15] and [16]. Other considerations are further discussed in the Results and Discussion section.

It is widely accepted that if $R Q_{\text {mix }} \geq 1$, the sample has a potential ecological risk for aquatic organisms, while if $\mathrm{RQ}_{\text {mix }}<1$, it has no potential ecological risk for aquatic organisms [17]. In addition, it needed to stress that although genotoxicity has attracted extensive attention, there are no reliable and abundant data for mixture genotoxicity prediction and risk assessment. 


\subsection{Data analysis}

Dose metrics of the water samples were expressed as the enrichment factor (EF) of the SPE, which was calculated as the volume of original water sample $\left(\mathrm{V}_{\text {watersample }}\right)$ divided by the volume of its SPE extract $\left(\mathrm{V}_{\text {extract }}\right)$, as shown in Eq. (3).

$$
E F(\text { times })=\frac{V_{\text {water sample }}(\mathrm{mL})}{V_{\text {extract }}(\mathrm{mL})}
$$

For acute toxicity to luminescent bacteria and genotoxicity, the $\mathrm{EC}_{50}$ or $\mathrm{IR}_{1.5}$ was derived from concentration (EF) - effect curves, and the toxicity of the water samples was then standardized to a toxic equivalent concentration (TEQ), which was expressed as the $\mathrm{EC}_{50}$ or $\mathrm{IR}_{1.5}$ of reference compound divided by the $\mathrm{EC}_{50}$ or $\mathrm{IR}_{1.5}$ of water sample (Eq.(4)).

$$
\mathrm{TEQ}(\mathrm{mg} / \mathrm{L} \text { or } \mu \mathrm{g} / \mathrm{L})=\frac{\mathrm{EC}_{50} \text { or } \mathrm{IR}_{1.5} \text { of reference compound }(\mathrm{mg} / \mathrm{L} \text { or } \mu \mathrm{g} / \mathrm{L})}{\left.\mathrm{EC}_{50} \text { or } \mathrm{IR}_{1.5} \text { of water sample(times }\right)}
$$

For phytotoxicity, it was difficult to apply TEQs as quantitative indices because of the low detected effect and the large volume of sample required for testing. So, the growth inhibition of SPE extracts of water samples ( $\mathrm{EF}=40$ times) was used directly to express the toxicity to $C$. vulgaris. Because of similar considerations, the toxicity of water samples without SPE concentration to fish larva was directly assayed. The reference compounds and quantitative evaluation indices used in bioassays are summarized in Table 1.

\begin{tabular}{|c|c|c|c|c|}
\hline Biotoxicity & Assay & Species & $\begin{array}{l}\text { Reference } \\
\text { compound }\end{array}$ & Index \\
\hline $\begin{array}{l}\text { Microorganism } \\
\text { toxicity }\end{array}$ & $\begin{array}{l}\text { Acute toxicity } \\
\text { to luminescent } \\
\text { bacteria }\end{array}$ & V. fischeri; Q67 & Phenol & TEQphenol \\
\hline Phytotoxicity & $\begin{array}{l}\text { Algal growth } \\
\text { inhibition test }\end{array}$ & C. vulgaris & $\begin{array}{l}\text { Potassium } \\
\text { dichromate } \\
(\mathrm{K} 2 \mathrm{Cr} 2 \mathrm{O} 7)\end{array}$ & $\begin{array}{l}\text { Growth } \\
\text { inhibition }\end{array}$ \\
\hline $\begin{array}{l}\text { Aquatic } \\
\text { vertebrates } \\
\text { toxicity }\end{array}$ & $\begin{array}{l}\text { fish larva } \\
\text { mortality test }\end{array}$ & Zebrafish & $\begin{array}{l}3,4- \\
\text { Dichloroaniline } \\
(3,4-D C A)\end{array}$ & Mortality \\
\hline Genotoxicity & SOS/umu test & $\begin{array}{l}\text { Salmonella } \\
\text { typhimurium } \\
\text { TA1535/pSK1002 }\end{array}$ & $\begin{array}{l}\text { 4-Nitroquinoline- } \\
\text { N-oxide (4-NQO) }\end{array}$ & TEQ4-NQO \\
\hline
\end{tabular}

Table 1. Bioassays and their quantitative evaluation indices used in this study. 


\section{Results and discussion}

\subsection{General water quality before and after storage}

As Table 2 shows, the reclaimed water generated by the $\mathrm{A}^{2} \mathrm{O}-\mathrm{MBR}$ system as well as the water stored in the lake achieved the requirements of the reclaimed water standard for toilet flushing, landscape water, and green-belt irrigation [18]. In general, the parameters reflecting inorganic content (such as $\mathrm{NH}_{4}{ }^{+}-\mathrm{N}$ and electric conductivity) decreased, while the parameters indicating the organic content $\left(\mathrm{COD}, \mathrm{TOC}\right.$, and $\left.\mathrm{UV}_{254}\right)$ and sensory indices (turbidity and color) increased after the reclaimed water was stored in the landscape lake. It has been universally acknowledged that the salinity of reclaimed water from urban WWTP is higher than that of source water (normally 1.5-2 times higher than that of tap water) [19]. Salts and nutrients in the reclaimed water may pose potential risks for the normal function of a landscape lake. Unexpectedly, the dissolved inorganic salts and nutrients in the reclaimed water decreased after entering the lake, suggesting that salts and nutrients from reclaimed water did not accumulate in the lake and that those entering the lake from reclaimed water and nonpoint sources did not exceed the environmental capacity of the lake. The natural water purification processes including seasonal uptake by macrophytes, biofouling onto foliage substrates, and feeding by organisms in higher trophic levels may contribute to the removal of salts and nutrients in inland lakes [20]. It is apparent that an open storage system has a high probability of suffering nonpoint pollution, which may cause the increases in turbidity, color, and so on. For example, the increased color of the stored reclaimed water in the lake may result from the transformation of some dissolved chemicals with chromophores that enter the lake water from nonpoint sources. The COD of lake water was more than three times the level of the reclaimed water, and there were slight increases in the $\mathrm{UV}_{254}$ and TOC, indicating that the higher COD in the lake water was not due to inputs of organic carbon from nonpoint sources.

Table 2. Normal physicochemical properties of the reclaimed water before and after storage in the landscape lake.

\begin{tabular}{lll}
\hline Parameters & Reclaimed water & Lake water \\
\hline COD (mg/L) & $7.18 \pm 4.11$ & $25.89 \pm 4.42$ \\
UV254 (1/cm) & $0.062 \pm 0.007$ & $0.072 \pm 0.008$ \\
TOC (mg/L) & $3.59 \pm 0.19$ & $5.45 \pm 1.05$ \\
SUVA (L/mgm) & $1.75 \pm 0.23$ & $1.35 \pm 0.17$ \\
TP (mg/L) & $0.41 \pm 0.13$ & $0.38 \pm 0.14$ \\
NH4+-N (mg/L) & $0.26 \pm 0.23$ & $0.22 \pm 0.22$ \\
TN (mg/L) & $12.81 \pm 3.49$ & $6.18 \pm 1.27$ \\
Electric conductivity ( $\mu$ s/cm) & $820.75 \pm 27.02$ & $711.63 \pm 39.86$ \\
Turbidity (NTU) & $1.35 \pm 0.09$ & $4.35 \pm 1.16$ \\
Color & $7.50 \pm 0.96$ & $27.6 \pm 5.19$ \\
\hline
\end{tabular}

Note: Values are presented as average value \pm standard deviation. There were 12 measurements during six months. 


\subsection{Occurrence of trace organic chemicals before and after storage}

\subsubsection{Detected chemicals}

Of the 59 trace organic chemicals, 52 chemicals including 12 PAHs, 15 phenols, three pesticides, and 22 pharmaceuticals were detected in the reclaimed water, while 42 chemicals consisting 13 PAHs, 12 phenols, one pesticide, and 16 pharmaceuticals were found in lake water (Fig. 2). There was a greater variety of chemicals in the reclaimed water than the lake water. For PAHs, 1,12-Benzoperylene was only detected in the lake water, but its detection rate was extremely low. Three phenols (4-chloro-3-methylphenol, 2-chlorophenol, and 2,6-dichlorophenol), two pesticides (chlorpyrifos and dichlorphos), and six pharmaceuticals (acetaminophen, chloramphenicol, diphenhydramine, lincomycin, trimethoprim, and venlafaxine) were founded only in the reclaimed water. The detected chemicals from reclaimed water and lake water were at the average concentrations ranging from 0.18 to $204.08 \mathrm{ng} / \mathrm{L}$, and most were lower than $10 \mathrm{ng} / \mathrm{L}$ (Table SI-2). These results are in the previously reported concentration ranges for reclaimed water and surface water [12], [21] and [22].

\subsubsection{Possible sources of increased trace organic chemicals}

Undoubtedly, trace organic chemicals in reclaimed water are derived from incomplete removal of pollutants in domestic wastewater or by-products of treatment processes. The residuals in the reclaimed water were the major direct source for trace organic chemicals entering the landscape lake, because most of the chemicals were detected in both reclaimed water and lake water (Fig. 2). However, nonpoint source pollution may be another significant pathway for trace organic chemicals to enter the landscape lake. The chemicals found in lake water, but not in reclaimed water, such as 1,12-benzoperylene, might be from nonpoint source pollution. Nevertheless, the new chemicals only from nonpoint source pollution were limited.

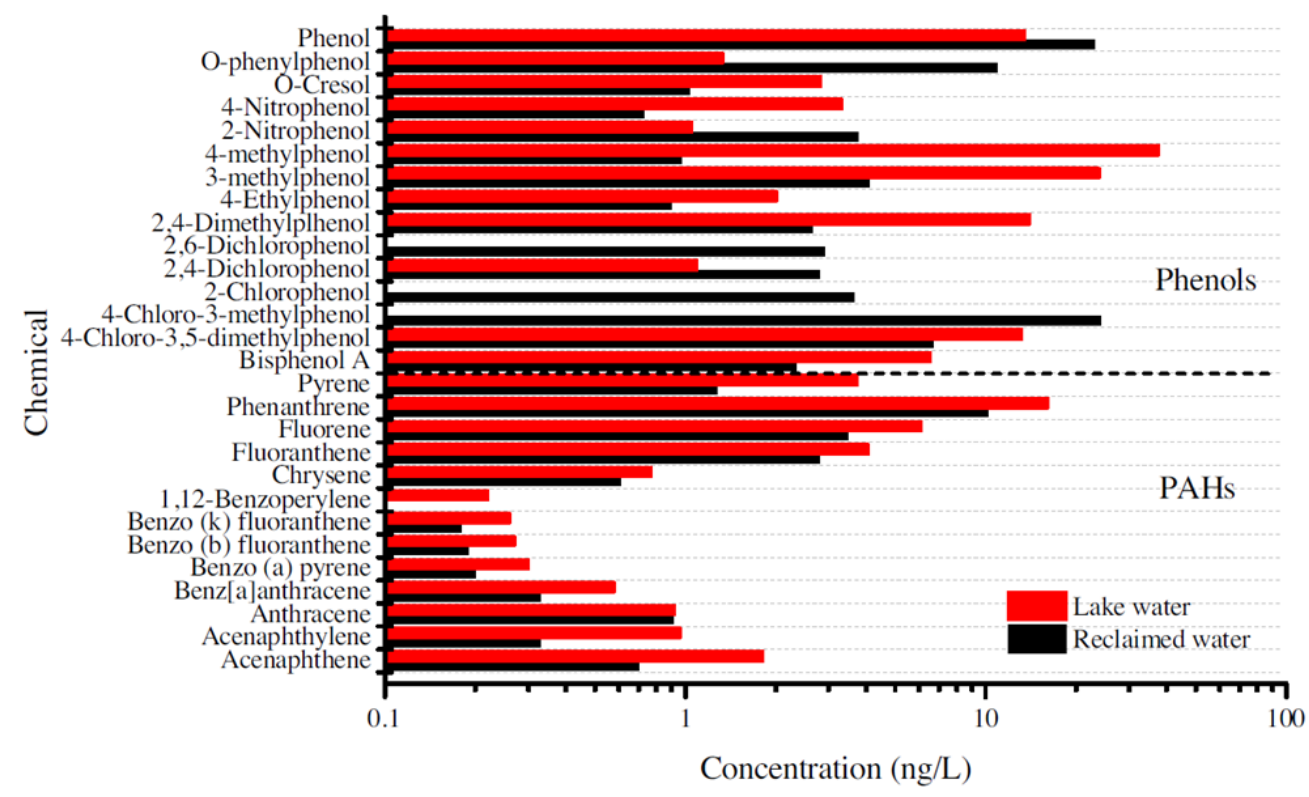




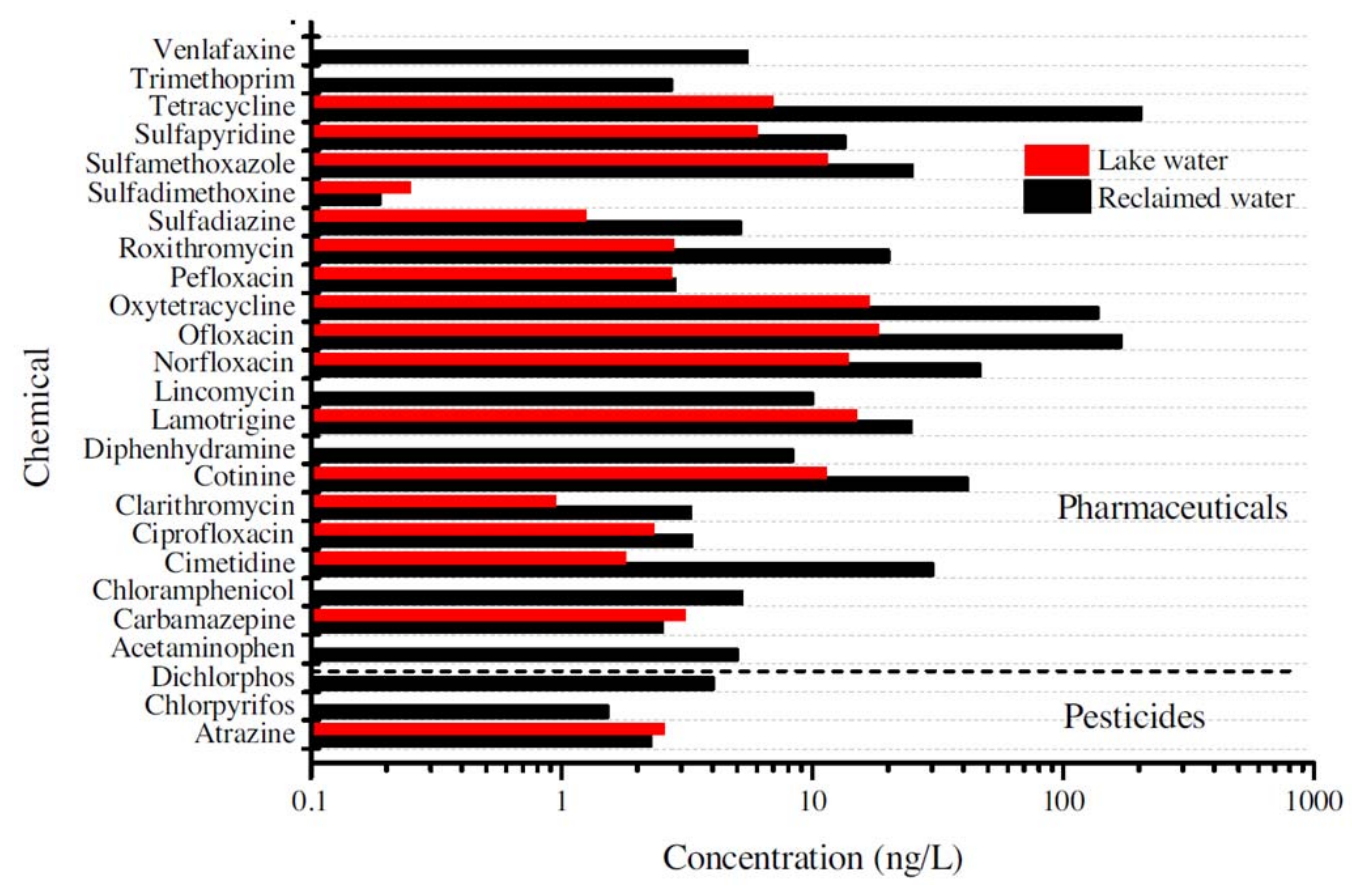

Fig. 2. Average concentrations of chemicals monitored in reclaimed water $(n=5)$ and lake water $(n=5)$. " $n$ " was the number of detected independent samples.

In addition, the total PAHs and phenols increased when reclaimed water was stored in the landscape lake (Fig. 3). Because of their lipophilicity and hydrophobicity characteristics, the concentrations of PAHs in water were strongly related with particulate concentration (such as turbidity) [23] and [24]. The turbidity of the lake water was much higher than that of the reclaimed water, corresponding to the increase in total PAHs (from 21.17 to $36 \mathrm{ng} / \mathrm{L}$ ). In fact, the concentrations of detected individual PAHs all increased after the reclaimed water entered the landscape lake. PAHs originate from the incomplete combustion of coal, petroleum, timber, and organic polymers, and are widely distributed in the environment [25]. It has been noted that the PAHs content in urban soil around the world is $98-23,250 \mu \mathrm{g} / \mathrm{kg}$, much higher than that in water [26]. Therefore, the observed increase in PAHs in the lake water likely originated from the ambient environment, such as from contaminated soil or atmospheric deposition [27].

Different changes in concentrations of individual phenols were found in the lake water, although the total concentration of phenols in water increased from 90.52 to $120.07 \mathrm{ng} / \mathrm{L}$ during storage in the landscape lake. For example, the concentration of 2,4-dimethylplhenol, 3-methylphenol, and 4-methylphenol increased dramatically, but 4-chloro-3-methylphenol, 2chlorophenol, and 2,6-dichlorophenol were not detected in the lake water (Fig. 2). Phenols can derive from degradation products or by-products of natural or artificial compounds (such as lignins and pesticides), or the by-products of the chlorine disinfection processes [28]. For example, the microbial degradation of chlorinated phenoxyalkanoic-acid pesticides, such as 2,4-dichlorophenoxyacetic acid and 2,4,5-trichlorophenoxyacetic acid, yields plenty of chlorophenols as intermediate metabolites [29] and [30]. Thus, in addition to nonpoint source 
pollution, the increase of phenols was likely due to the degradation products or by-products in the seminatural system.

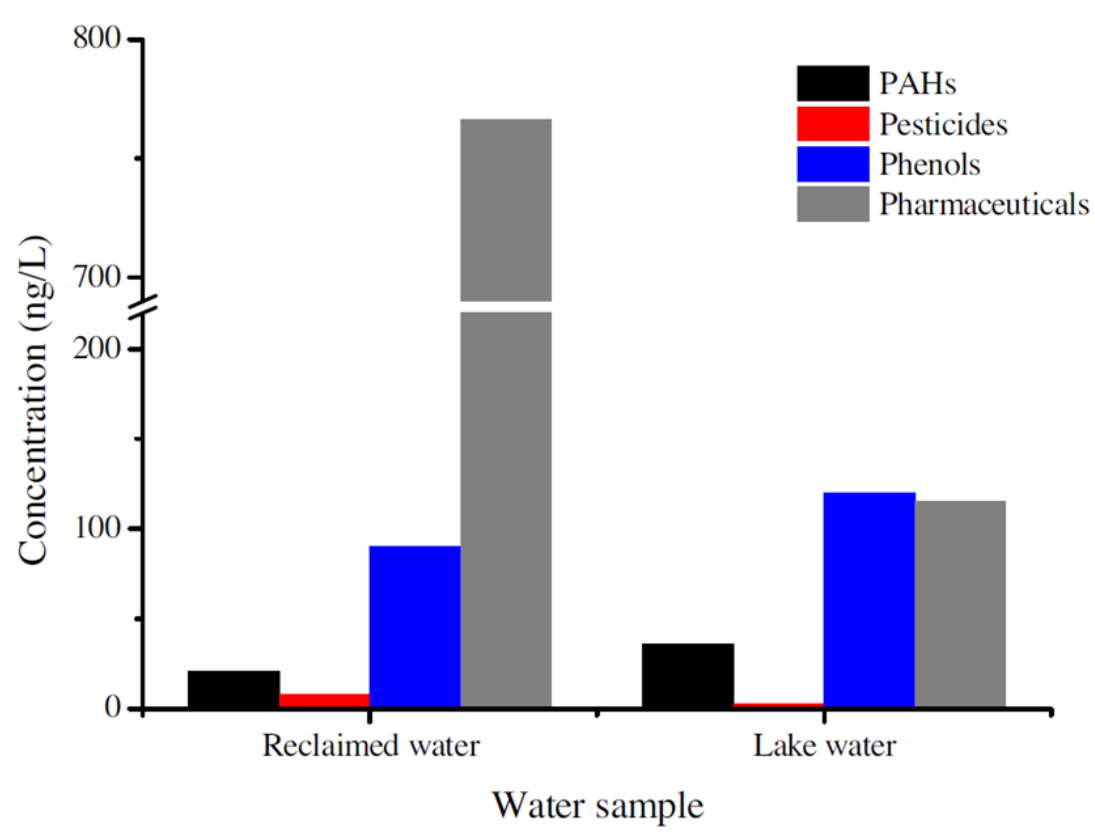

Fig. 3. Total concentration of chemicals monitored in reclaimed water and open-stored water.

\subsubsection{Decay of trace organic chemicals after water storage}

Of the four categories of trace organic chemicals, the total concentrations of pesticides and pharmaceuticals decreased after storage in the landscape lake (Fig. 3). Because the single source of raw wastewater was the domestic wastewater of schoolyard where pesticides were rarely used, only three pesticides, including one herbicide and two insecticides, were found in the produced reclaimed water. Of the three detected pesticides, atrazine is one of the most widespread herbicides in the world and its existence and inefficient removal in WWTPs have been reported previously [22] and [31]. Chlorpyrifos and dichlorphos are also a focus of increasing concern and their occurrence varies with usage in different areas [32] and [33]. Although these pesticides were not completely removed by the sophisticated treatment processes resulting in residuals in the reclaimed water (Table SI-2), chlorpyrifos and dichlorphos were not detected after open storage (Fig. 2), which suggests that the seminatural system promotes chlorpyrifos and dichlorphos removal.

The wide distribution of pharmaceuticals in the environment has been blamed for their presence in effluent discharge from WWTPs [21]. Miège et al. created a database using the results of 117 scientific publications to summarize the occurrence of pharmaceuticals in WWTPs [34]. Most of the pharmaceuticals detected in the reclaimed water in the present study were identified in the database as the frequently detected pharmaceuticals. However, as shown in Fig. 2, 22 pharmaceuticals were detected in the reclaimed water mostly with concentrations of $10^{0}-10^{2} \mathrm{ng} / \mathrm{L}$ orders, in contrast to 16 pharmaceuticals detected from the lake water mostly with concentrations of $10^{0}-10^{1} \mathrm{ng} / \mathrm{L}$ orders, while six pharmaceuticals 
were undetectable in the lake water. In the reclaimed water, the concentrations of ofloxacin, oxytetracycline, and tetracycline were as high as 100-200 ng/L, but in the lake water, their concentrations were decreased by one order of magnitude or more. As a result, the total concentration of the detected pharmaceuticals decreased from $766.27 \mathrm{ng} / \mathrm{L}$ in the reclaimed water to $115.28 \mathrm{ng} / \mathrm{L}$ in the lake water (Fig. 3). It has been reported that some antibiotics may undergo cleavage in natural water due to oxidation driven by solar photolysis [35], [36] and [37]. The activities in the natural environment can significantly stimulate the removal of pharmaceuticals.

\subsection{Toxicities before and after storage based on bioassays}

For the acute toxicity tests using $V$. fischeri and Q67, the inhibitory effect of reclaimed water expressed as TEQ ${ }_{\text {phenol }}$ was reduced from 7.12 to $4.14 \mathrm{mg} / \mathrm{L}$ for $V$. fischeri and from 18.96 to $6.20 \mathrm{mg} / \mathrm{L}$ for Q67 during open storage (Fig. 4). This indicates that natural water purification processes in the landscape lake decreased the acute toxicity of reclaimed water based on organisms at the lowest trophic level.

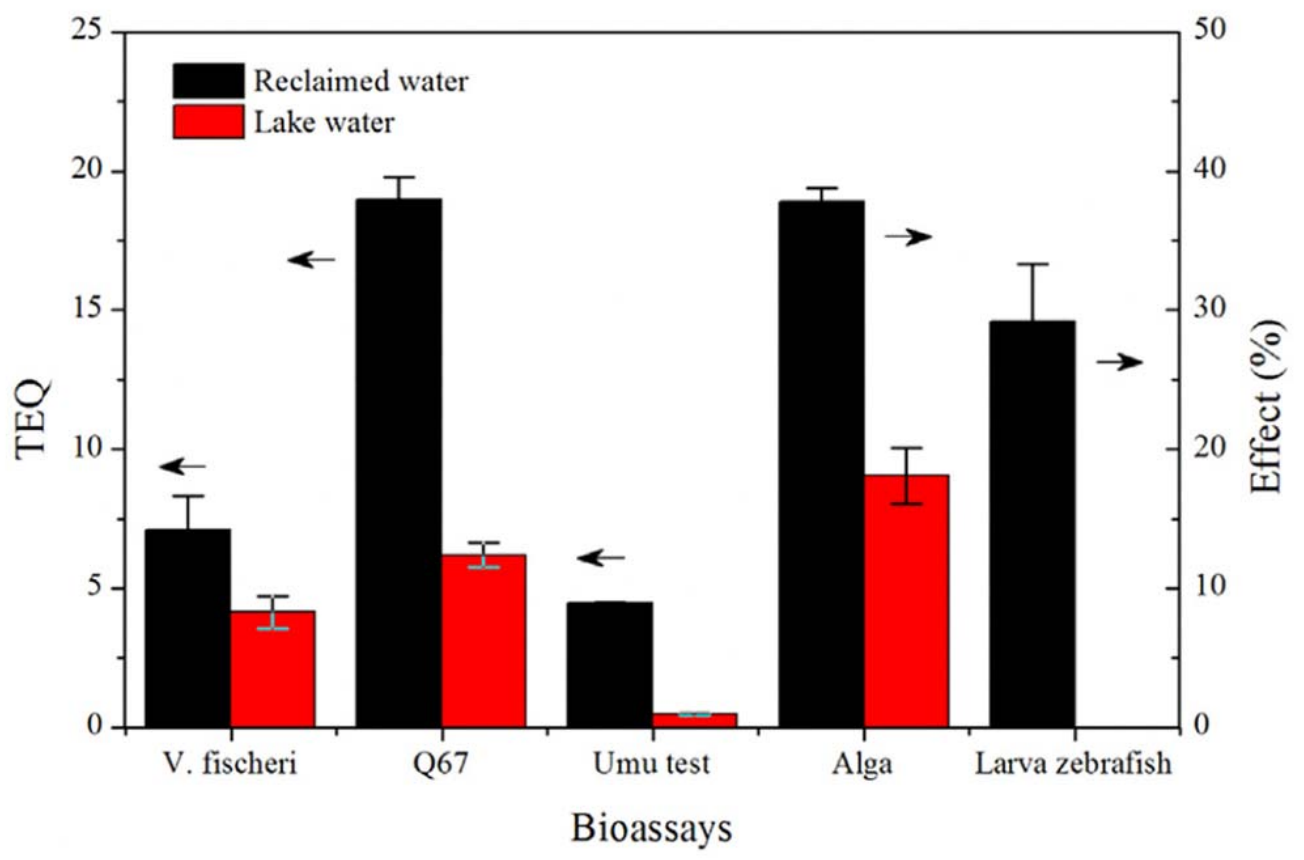

Fig. 4. Results of five bioassays. Luminescent bacteria toxicity test of water sample extracts using $V$. fischeriand Q67 was denoted as TEQphenol $(\mathrm{mg} / \mathrm{L})$. Similarly, the SOS/umu test of water sample extracts was expressed as $\mathrm{TEQ}_{4-\mathrm{NQO}}(\mu \mathrm{g} / \mathrm{L})$. Algal growth inhibition tests of water sample extracts $(\mathrm{EF}=40$ times) were expressed as inhibition at $72 \mathrm{~h}$ exposure $(\%)$. Fish larva test of water samples without enrichment was denoted as mortality (\%) at $96 \mathrm{~h}$ exposure. The number of detected independent samples was 5 for every bioassay.

In this study, even after many-fold enrichment, the water samples still showed very low phytotoxicity, and the effective concentration corresponding to $50 \%$ inhibition could not be experimentally obtained. This might be due to the low concentrations of detected pesticides 
which were closely related to photosynthesis inhibition [38]. After $72 \mathrm{~h}$ exposure with $\mathrm{EF}=40$ times, the inhibition value decreased from $37.77 \%$ for the reclaimed water to $18.11 \%$ for the lake water (Fig. 4), indicating that the landscape lake could achieve phytotoxicity removal to certain extent.

For the aquatic vertebrate toxicity test, zebrafish larvae without chorions were used in the test for eliminating the action of chorions of zebrafish embryos as barriers against toxicant uptake, especially for high-molecular-weight chemicals [39]. To avoid the interference of cosolvent (dimethyl sulfoxide solution), actual non-concentrated water samples were used in the zebrafish larvae test. After $96 \mathrm{~h}$ exposure to the reclaimed water, 29.17\% of larvae death was detected in contrast to non-negative effects for the lake water (Fig. 4). The landscape lake, as a seminatural ecosystem, effectively eliminated the adverse effect of the reclaimed water on zebrafish larvae. Moreover, it was observed that the reclaimed water did not lead to zebrafish larvae death until exposure of $72 \mathrm{~h}$, while the mortality increased suddenly in the remaining exposure period ( $72-96 \mathrm{~h}$ ). It was speculated that the action of the pollutants in the reclaimed water on larvae was relatively slow.

Regarding the genotoxicity, in the SOS/umu assay without metabolic activation, the TEQ 4 NQO decreased from $4.46 \mu \mathrm{g} / \mathrm{L}$ in the reclaimed water to $0.48 \mu \mathrm{g} / \mathrm{L}$ in the lake water, indicating that the open storage in the seminatural ecosystem greatly assisted genotoxicity removal.

In common sense, the $\mathrm{A}^{2} \mathrm{O}-\mathrm{MBR}$ units employed for water reclamation is an advanced treatment system for effective removal of suspended, colloidal pollutants, and biodegradable organic substances to produce water suitable for reuse. However, as a result of the biotoxicity analysis in this study, the reclaimed water still exihibited apparent toxic effects on aquatic organisms of different trophic levels, as well as significant genotoxicity. Nevertheless, after the reclaimed water was led to the landscape lake, these toxic effects were much significantly reduced or even eliminated during water storage. Although biotoxicity is not a direct measure of any specified contaminant, it is contributed by the integral effects of residual contaminants which pose adverse effects on aquatic organisms. The apparent reduction of the detected trace organic chemicals during the open storage of the reclaimed water in the landscape lake could provide explanations on such kind of relationships based on reported studies which indicated the toxicity of specific chemicals [40]. Taking genotoxicity as an example, PAHs, pesticides (e.g. atrazine), phenols (e.g. 2-chlorophenol) and PPCPs (e.g. ofloxacin) are potential genotoxins [41], [42], [43] and [44]. Some disinfection by-products (DBPs), not discussed in this study, may also contribute to genotoxicity [45]. In a seminatural ecosystem, such as the landscape lake in this study, naturally occurring physical, chemical, physicochemical, biological and ecological actions may stimulate the decomposition of the above mentioned trace organic to substantially reduce genotoxicity.

\subsection{Identification of dominating toxic chemicals based on risk quotient estimation}

The acute toxicity data based on four species including bacteria, algae, daphnia, and fish were used to estimate the RQ. The value assigned to AF seriously affected the PNEC estimation 
that was used to calculate RQ. The Technical Guidance Document of the European Commission suggested that AF was set as 1000 if acute toxicity data are available in at least three test systems on three trophic levels: algae, daphnia, and fish[15]. In this study, acute toxicity data regarding bacteria ( $V$. fischeri) was also introduced to estimate PNEC. There were no guidance documents or studies to confirm AF value in this case. Guidance for the Implementation of REACH stated that $V$. fischeri(MICROTOX ${ }^{\circledR}$ test) has limited relevance with WWTP function [16]. So, there was no recommended AF for the effect assessment of microorganisms in WWTP. However, it was different with the objective of calculating PNEC in this study. That was because acute toxicity of chemicals in water towards $V$. fischeri has a close relationship with its ecological risk. Comparison of the collected $\mathrm{L}(\mathrm{E}) \mathrm{C}_{50}$ values of target trace organic chemicals for the four species revealed that daphnia was the most sensitive species to most target trace organic chemicals except PAHs, to which $V$. fischeri was the most sensitive species. Because of the low concentration of PAHs in water sample, the PNECs of PAHs showed little influence on the estimated result of $\mathrm{RQ}_{\text {Total. }}$. The PNECs of target chemicals were mainly affected by one species (daphnia). Hence, the AF was set as 1000 in this study.

The $\mathrm{RQ}_{\text {Total }} \mathrm{S}$ of reclaimed water and lake water are shown in Table 3, as well as those of raw wastewater and the secondary effluent for biotoxicity tracking. The RQ $\mathrm{Q}_{\mathrm{Total}} \mathrm{S}$ of wastewater, secondary effluent, and reclaimed water exceeded one and only the RQ $\mathrm{T}_{\mathrm{Tota}}$ of lake water was less than one. This indicated that all the water samples except lake water had potential ecological risk for aquatic organisms. The ecological safety of reclaimed water improved after reserving into the landscape lake, although non-point source pollution introduced some contaminants. This further verified the above biotoxicity test results for reclaimed water and lake water. The lake as a part of campus landscape could not only adjust the amount of water required as a buffer zone, but also improve the ecological safety of reclaimed water for subsequent reuse.

The RQs of target chemicals are shown in Table SI-3. The RQs of the dominating trace organic chemicals in the water samples are shown in Table 3. Chlorpyrifos and dichlorphos, which had RQs exceeding 1, made the greatest contribution to the biotoxicity of wastewaters from reclaimed water production processes (as shown in bold in Table 3). This is because the chlorpyrifos and dichlorphos are extremely toxic to daphnia even in very low concentrations (Table SI-3). Therefore, these two insecticides should receive more attention than other trace organic chemicals in the ecosystem, even though pesticides were not the primary trace organic chemicals based on chemical analysis. Furthermore, 4-methylphenol, acetaminophen, and tetracycline had high concentrations in the water samples and contributed greatly to $\mathrm{RQ}_{\text {total }}$, as shown in Table 3. It is clear that ecological risk reduction of reclaimed water stored in the lake occurred mainly because of the decreased risk from chlorpyrifos, dichlorphos, and tetracycline, which can be tracked to raw wastewater. The concentration reduction of other chemicals in lake water had a certain contribution to reduce its adverse impact on ecological system and then the trace organic chemicals introduced into the lake water by non-point source or treatment processes could not increase the ecological risk observably. 
Table 3. The dominating ecological risk quotients (RQs) of trace organic chemicals based on the mean concentrations in water samples.

\begin{tabular}{lllll}
\hline Chemicals & Wastewater & Secondary effluent & Reclaimed water & Lake water \\
\hline Chlorpyrifos & $5.26 \mathrm{E}+00$ & $4.20 \mathrm{E}+00$ & $4.59 \mathrm{E}+00$ & - \\
Dichlorphos & $1.24 \mathrm{E}+00$ & $9.55 \mathrm{E}-02$ & $1.30 \mathrm{E}-01$ & - \\
4-Methylphenol & $8.34 \mathrm{E}-01$ & $4.15 \mathrm{E}-04$ & $1.86 \mathrm{E}-04$ & $7.19 \mathrm{E}-03$ \\
Acetaminophen & $4.43 \mathrm{E}-01$ & - & $3.03 \mathrm{E}-03$ & - \\
Tetracycline & $1.02 \mathrm{E}-01$ & $1.11 \mathrm{E}-01$ & $7.12 \mathrm{E}-02$ & $2.44 \mathrm{E}-03$ \\
Total & $8.40 \mathrm{E}+00$ & $4.68 \mathrm{E}+00$ & $5.12 \mathrm{E}+00$ & $3.07 \mathrm{E}-01$ \\
\hline
\end{tabular}

Note: The chemicals with RQ values greater than 0.1 are shown in the table. The chemicals with RQ values greater than 1 are shown in bold. The "Total" was calculated based on all target chemicals.

\section{Conclusion}

Water reuse through a water cycle is an effective way to realize multi-step utilization of the reclaimed water as shown by the system investigated in this study. Within the water cycle, the landscape lake acts as a quantitative and qualitative buffer zone between reclaimed water production and reuse. In addition to its primary function of water landscaping, the lake acts as a reservoir for open-storage of the reclaimed water and inevitably receives non-point pollutant sources. Therefore, it has been uncertain whether the water after storage still meets the quality requirements for subsequent reuse. Through this study, it was identified that although the lake water was slightly deteriorated comparing with the reclaimed water regarding certain conventional parameters such as COD, TOC, turbidity and color, many of the trace organic chemicals detected from the reclaimed water were substantially reduced during water storage. This eventually resulted in a remarkable reduction of the biotoxicity as indicated by the toxicity on aquatic organisms of various trophic levels and genotoxicity, and the $\mathrm{RQ}_{\text {Total }}$ as a comprehensive index for quantifying the ecological risk level. The method of RQs estimation for each detected trace organic chemical has effectively assisted identifying the dominating toxic organic chemicals contributing to the biotoxicity and helped us to clarify the main reasons for toxicity reduction in the lake water. It can thus be concluded that the seminatural environment of the landscape lake has provided a favorable condition for the decay of toxic trace organic chemicals to improve the ecological safety of the stored water. Further studies are still necessary for investigating how certain trace organic chemicals residual in the reclaimed water are reduced during open storage in such a system. 


\section{Acknowledgements}

This research was supported by the National Natural Science Foundation of China(Grant No. 51508449), the National Program of Water Pollution Control in China (Grant No. 2013ZX07310-001), Fund for Postdoctoral Scientific Research Project, China(2015M572531) and the Program for Innovative Research Team in Shaanxi (Grant No.IRT2013KCT-13). The authors are grateful to Mr. Oda Yoshimitsu for the provision of Salmonella typhimurium TA1535/pSK1002.

\section{References}

[1] Z. Li, X. Xiang, M. Li, Y. Ma, J. Wang, X. Liu, Occurrence and risk assessment of pharmaceuticals and personal care products and endocrine disrupting chemicals in reclaimed water and receiving groundwater in China, Ecotox. Environ. Safe. 119 (2015) $74-80$.

[2] A. Jia, B.I. Escher, F.D.L. Leusch, J.Y.M. Tang, E. Prochazka, B. Dong, E.M. Snyder, S.A. Snyder, In vitro bioassays to evaluate complex chemical mixtures inrecycled water, Water Res. 80 (2015) 1-11.

[3] O. Mahjoub, M. Leclercq, M. Bachelot, C. Casellas, A. Escande, P. Balaguer, A.Bahri, E. Gomez, H. Fenet, Estrogen, aryl hysdrocarbon and pregnane Xreceptors activities in reclaimed water and irrigated soils in Oued Souhil area(Nabeul Tunisia), Desalination 246 (2009) 425-434.

[4] B.I. Escher, M. Allinson, R. Altenburger, P.A. Bain, P. Balaguer, W. Busch, J.Crago, N.D. Denslow, E. Dopp, K. Hilscherova, A.R. Humpage, A. Kumar, M.Grimaldi, B.S. Jayasinghe, B. Jarosova, A. Jia, S. Makarov, K.A. Maruya, A.Medvedev, A.C. Mehinto, J.E. Mendez, A. Poulsen, E. Prochazka, J. Richard, A.Schifferli, D. Schlenk, S. Scholz, F. Shiraish, S. Snyder, G.Y. Su, J.Y.M. Tang, B.van der Burg, S.C. van der Linden, I. Werner, S.D. Westerheide, C.K.C. Wong, M.Yang, B.H.Y. Yeung, X.W. Zhang, F.D.L. Leusch, Benchmarking organic micropollutants in wastewater, recycled water and drinking water with In vitro bioassays, Environ. Sci. Technol. 48 (2014) 1940-1956.670 X.Y. Ma et al. / Journal of Hazardous Materials 318 (2016) 663-670

[5] F.D.L. Leusch, S.J. Khan, M.M. Gagnon, P. Quayle, T. Trinh, H. Coleman, C.Rawson, H.F. Chapman, P. Blair, H. Nice, T. Reitsema, Assessment ofwastewater and recycled water quality: a comparison of lines of evidencefrom in vitro, in vivo and chemical analyses, Water Res. 50 (2014) 420-431.

[6] V. Kokkali, W. van Delft, Overview of commercially available bioassays for assessing chemical toxicity in aqueous samples, TrAC Trend Anal. Chem. 61(2014) 133-155.

[7] J. Xu, C. Zhao, D. Wei, Y. Du, A toxicity-based method for evaluating safety ofreclaimed water for environmental reuses, J. Environ. Sci. 26 (2014)1961-1969. 
[8] A. Dominguez-Chicas, M.D. Scrimshaw, Hazard and risk assessment forindirect potable reuse schemes: an approach for use in developing WaterSafety Plans, Water Res. 44 (2010) 6115-6123.

[9] H.J. Zhao, Y. Wang, L.L. Yang, L.W. Yuan, D.C. Peng, Relationship between phytoplankton and environmental factors in landscape water supplemented with reclaimed water, Ecol. Indic. 58 (2015) 113-121.

[10] X.C. Wang, C. Zhang, X. Ma, L. Luo, Water Cycle Management-A New Paradigm of Wastewater Reuse and Safety Control, Springer briefs in water science and technology, 2015.

[11] S.E.P.A. (State Environmental Protection Administration), Water and Wastewater Monitoring Method, 4th ed., China Environmental Science Press,Beijing, 2006.

[12] J. Sun, Q. Luo, D. Wang, Z. Wang, Occurrences of pharmaceuticals in drinking water sources of major river watersheds, China, Ecotox. Environ. Safe. 117(2015) 132-140.

[13] W. Chen, S. Lu, N. Pan, Y. Wang, L. Wu, Impact of reclaimed water irrigation on soil health in urban green areas, Chemosphere 119 (2015) 654-661.

[14] J. Sánchez-Avila, R. Tauler, S. Lacorte, Organic micropollutants in coastal waters from NW Mediterranean Sea: sources distribution and potential risk, Environ. Inter. 46 (2012) $50-62$.

[15] European Commission, Technical Guidance Document in Support of Commission Directive 93/67/EEC on Risk Assessment for New Notified Substances, Commission Regulation (EC) No 1488/94 on Risk Assessment for Existing Substances, and Directive 98/8/EC of the European Parliament and of the Council Concerning the Placing of Biocidal Products on the Market, Office for Official Publications of the European Communities, Luxembourg, 2003.

[16] European Chemicals Agency, Guidance on Information Requirements and Chemical Safety Assessment Chapter R. 10: Characterisation of Dose [Concentration] - Response for Environment, 2008.

[17] E. Cho, J. Khim, S. Chung, D. Seo, Y. Son, Occurrence of micropollutants in four major rivers in Korea, Sci. Total Environ. 491-492 (2014) 138-147.

[18] Ministry of Water Resources, China, SL368-2006 Standards of Reclaimed Water Quality, 2006.

[19] W. Chen, S. Lu, W. Jiao, M. Wang, A.C. Chang, Reclaimed water: a safeirrigation water source? Environ. Dev. 8 (2013) 74-83.

[20] K. Taguchi, K. Nakata, Evaluation of biological water purification functions ofinland lakes using an aquatic ecosystem model, Ecol. Model. 220 (2009)2255-2271.

[21] B. Petrie, R. Barden, B. Kasprzyk-Hordern, A review on emerging contaminants in wastewaters and the environment: current knowledge, understudied areas and recommendations for future monitoring, Water Res. 72 (2015) 3-27. 
[22] Y. Luo, W. Guo, H.H. Ngo, L.D. Nghiem, F.I. Hai, J. Zhang, S. Liang, X.C. Wang, Areview on the occurrence of micropollutants in the aquatic environment and their fate and removal during wastewater treatment, Sci. Total Environ.473-474 (2014) 619-641.

[23] S. Rabodonirina, S. Net, B. Ouddane, D. Merhaby, D. Dumoulin, T. Popescu, P.Ravelonandro, Distribution of persistent organic pollutants (PAHs, Me-PAHsPCBs) in dissolved, particulate and sedimentary phases in freshwater systems, Environ. Pollut. 206 (2015) 38-48.

[24] M. Hijosa-Valsero, E. Bécares, C. Fernández-Aláez, M. Fernández-Aláez, R.Mayo, J.J. Jiménez, Chemical pollution in inland shallow lakes in the Mediterranean region (NW Spain): PAHs, insecticides and herbicides in water and sediments, Sci. Total Environ. 544 (2016) 797-810.

[25] A. Rubio-Clemente, R.A. Torres-Palma, G.A. Pẽnuela, Removal of polycyclic aromatic hydrocarbons in aqueous environment by chemical treatments: a review, Sci. Total Environ. 478 (2014) 201-225.

[26] Y. Jiang, U.J. Yves, H. Sun, X. Hu, H. Zhan, Y. Wu, Distribution, compositional pattern and sources of polycyclic aromatic hydrocarbons in urban soils of an industrial city Lanzhou, China, Ecotox. Environ. Safe. 126 (2016) 154-162.

[27] W. Qi, H. Liu, B. Pernet-Coudrier, J. Qu, Polycyclic aromatic hydrocarbons in wastewater, WWTPs effluents and in the recipient waters of Beijing, China, Environ. Sci. Pollut. Res. 20 (2013) 4254-4260.

[28] A. Gentili, S. Marchese, D. Perret, MS techniques for analyzing phenols, their metabolites and transformation products of environmental interest, TrACTrend. Anal. Chem. 27 (2008) 888-903.

[29] M. Czaplicka, Sources and transformations of chlorophenols in the natural environment, Sci. Total Environ. 322 (2004) 21-39.

[30] A.O. Olaniran, E.O. Igbinosa, Chlorophenols and other related derivatives of environmental concern: properties, distribution and microbial degradation processes, Chemosphere 83 (2011) 1297-1306.

[31] J. Campo, A. Masiá, C. Blasco, Y. Picó, Occurrence and removal efficiency of pesticides in sewage treatment plants of four Mediterranean River Basins, J.Hazard. Mater. 263 (Part 1) (2013) 146-157.

[32] M. Clara, G. Windhofer, P. Weilgony, O. Gans, M. Denner, A. Chovanec, M.Zessner, Identification of relevant micropollutants in Austrian municipal wastewater and their behaviour during wastewater treatment, Chemosphere87 (2012) 1265-1272.

[33] R. Mailler, J. Gasperi, Y. Coquet, A. Buleté, E. Vulliet, S. Deshayes, S. Zedek, C.Mirande-Bret, V. Eudes, A. Bressy, E. Caupos, R. Moilleron, G. Chebbo, V.Rocher, Removal of a wide range of emerging pollutants from wastewater treatment plant discharges by micro-grain activated carbon in fluidized bed as tertiary treatment at large pilot scale, Sci. Total Environ. 542 (Part A) (2016)983-996. 
[34] C. Miège, J.M. Choubert, L. Ribeiro, M. Eusèbe, M. Coquery, Fate of pharmaceuticals and personal care products in wastewater treatment plants - conception of a database and first results, Environ. Pollut. 157 (2009)1721-1726.

[35] M.N. Abellán, J. Giménez, S. Esplugas, Photocatalytic degradation of antibiotics: the case of sulfamethoxazole and trimethoprim, Catal. Today 144(2009) 131-136.

[36] C. Sirtori, A. Agüera, W. Gernjak, S. Malato, Effect of water-matrix composition on Trimethoprim solar photodegradation kinetics and pathways, Water Res.44 (2010) 27352744.

[37] M. Długosz, P.'Zmudzki, A. Kwiecie'n, K. Szczubiałka, J. Krzek, M. Nowakowska, Photocatalytic degradation of sulfamethoxazole in aqueous solution using a floating TiO2-expanded perlite photocatalyst, J. Hazard. Mater. 298 (2015)146-153.

[38] J.Y.M. Tang, F. Busetti, J.W.A. Charrois, B.I. Escher, Which chemicals drive biological effects in wastewater and recycled water? Water Res. 60 (2014)289-299.

[39] T. Lin, Y. Chen, W. Chen, Impact of toxicological properties of sulfonamides on the growth of zebra fish embryos in the water, Environ. Toxicol. Pharm. 36(2013) 10681076.

[40] A. Pal, Y. He, M. Jekel, M. Reinhard, K.Y.-H. Gin, Emerging contaminants of public health significance as water quality indicator compounds in the urban water cycle, Environ. Int. 71 (2014) 46-62.

[41] S. Senthilkumar, A. Manju, P. Muthuselvam, D. Shalini, V. Indhumathi, K.Kalaiselvi, M. Palanivel, P.P. Chandrasekar, P. Rajaguru, Characterization and genotoxicity evaluation of particulate matter collected from industrial atmosphere in Tamil Nadu State, India, J. Hazard. Mater. 274 (2014) 392-398.

[42] D. Vlastos, M. Antonopoulou, I. Konstantinou, Evaluation of toxicity and genotoxicity of 2-chlorophenol on bacteria, fish and human cells, Sci. Total Environ. 551-552 (551) (2016) 649-655.

[43] J.A. Adeyemi, A. da Cunha Martins-Junior, F. Barbosa Jr., Teratogenicity, genotoxicity and oxidative stress in zebrafish embryos (Danio rerio)co-exposed to arsenic and atrazine, Comp, Biochem. Phys. 172-173 (172)(2015) 7-12.

[44] R. Andreozzi, M. Raffaele, P. Nicklas, Pharmaceuticals in STP effluents and their solar photodegradation in aquatic environment, Chemosphere 50 (2003)1319-1330.

[45] Q.Y. Wu, Y. Li, H.Y. Hu, Y.X. Sun, F.Y. Zhao, Reduced effect of bromide on the genotoxicity in secondary effluent of a municipal wastewater treatment plant during chlorination, Environ. Sci. Technol. 44 (2010) 4924-4929. 